\title{
O trabalho da crítica
}

\author{
[ The labour of criticism
}

\section{Maria Elisa Cevasco ${ }^{\mathrm{I}}$}

RESUMO - Este artigo pretende examinar, através da leitura de ensaios-chave de Roberto Schwarz, o poder de elucidação da crítica cultural. P PALAVRAS-CHAVE • Crítica cultural; Roberto Schwarz. - ABSTRACT .
This article intends to examine the power of clarification of cultural criticism. This will be done presenting an analysis of key-essays by Roberto Schwarz. • KEYWORDS · Cultural criticism; Roberto Schwarz.

Recebido em I2 de abril de 2019

Aprovado em II de novembro de $20 \mathrm{I9}$

CEVASCO, Maria Elisa. O trabalho da crítica. Revista do Instituto de Estudos Brasileiros, Brasil, n. 74, p. 8I-96, dez. 2019 .

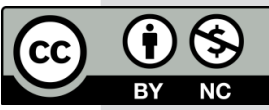

DOI: http://dx.doi.org/10.11606/issn.2316-901X.v0i74p81-96

I Universidade de São Paulo (USP, São Paulo, SP, Brasil). 
If you can look into the seeds of time And say which grain will grow, and which will not, Speak, then, to me, who neither beg nor fear Your favors nor your hate.

(William Shakespeare).

Em uma entrevista, falando sobre a função da crítica cultura, Roberto Schwarz explicita:

Se não for preciso adivinhar, pesquisar, construir, recusar aparências, consubstanciar intuições difíceis, a crítica não é crítica. Para a crítica dialética, o trabalho da figuração literária é um modo substantivo de pensamento, uma via sui generis de pesquisa, que aspira à consistência e tem exigência máxima. Seu resultado não é a simples reiteração da experiência cotidiana, a cuja prepotência se opõe, cujas contradições explicita, cujas tendências acentua, com decisivo resultado de clarificação. (SCHWARZ, 20I2b, p. 287-288).

Penso que uma maneira produtiva de mostrar a relevância de sua obra para o debate cultural contemporâneo é apresentar de que modo ele cumpre à risca esse programa, que, não por acaso, é o da crítica materialista, que tem como um de seus objetivos elevar o presente ao pensamento. Com ele aprendemos todos, no Brasil e fora dele, através das traduções e publicações sobre sua obra, a pensar o mundo que nos cerca pelo ângulo da produção cultural, que concretiza os significados e valores de determinada sociedade, e os torna visíveis e disponíveis para o esclarecimento de todos.

Começando pelo mais recente. Todos sabemos que o ano de 2016 foi marcado por mais um dos surtos de polarização política que afetam as sociedades desiguais como a brasileira, recorrentemente às voltas com o difícil problema da construção, sempre abortada, de uma sociedade integrada. O cenário de uma crise econômica que, como tantas outras, bate mais forte na periferia impulsiona uma crise política que desemboca em duas correntes opostas, uma defendendo o impeachment da presidente reeleita por pequena margem em 20I4, e outra defendendo que isso seria apenas um golpe disfarçado de procedimento jurídico-constitucional. Como também acontece 
nas sociedades cujas relações são fortemente moldadas pelas simplificações tão caras aos meios de comunicação de massa, a discussão fica empacada entre as duas posições antagônicas, e tudo o que parecia interessar é quem é contra e quem é a favor do impeachment, sem levar em conta os pressupostos históricos e as projeções políticas, além, é claro, a concepção do país que cada posição encerra. Em uma palavra, falta o fundamental, ou seja, a relação entre a parte e o todo que a determina. Do ponto de vista do momento em que escrevo, 20I9, fica evidente que estava aí germinando uma semente daninha que iria marcar o tempo. No meio do tumulto de opiniões e manifestos, um grande jornal diário resolve perguntar a intelectuais renomados de que lado cada um está. A resposta de Roberto contém, em miniatura, seus procedimentos críticos e a maneira como estes vão ao cerne dos fenômenos, desvelando por onde passam as verdadeiras correntes da história que moldam a discussão:

Vou responder indiretamente. A Folha e O Estado de S. Paulo acabam de publicar um manifesto assinado por talvez 500 associações empresariais, exigindo o impeachment já e afirmando que "chega de pagar o pato". O anúncio ocupa um bloco de I4 meias páginas dos dois jornais, o que deve ter custado um bom dinheiro. A motivação é econômico-política, e não jurídica. A forma é publicitária. O tom é de quem manda.

De outro lado, está na internet um manifesto das "Periferias Contra o Golpe", assinado por cerca de 400 associações culturais. Digamos que se trata de uma fração esclarecida e auto-organizada do povão. Sem defender as políticas do governo, o documento se contrapõe à casa-grande e exige respeito ao resultado das urnas. A redação é viva e substanciosa. A nota é muito popular-brasileira, atravessada pela mestiçagem e pelo clima da grande periferia urbana. Para dar uma ideia da diversidade, o manifesto é assinado por coletivos pela moradia, centros de educação popular, núcleos de teatro, cinema, poesia e dança, um blog antimachista, mulheres do hip-hop, uma assessoria jurídica universitária popular, tudo em espírito libertário.

É claro que o Brasil não se resume a esta oposição. Entretanto ela dá o que pensar. (SCHWARZ, 20I6, p. 6).

Como sempre faz, Roberto examina as manifestações da contradição social e mostra o que as estrutura. Estamos diante de mais uma das exposições do que ele mesmo denomina de "a matéria brasileira", a constelação formada pelo complexo peculiar de relações e posições que constituem nossa vida local. Como bom crítico literário que é, examina, ainda que da maneira breve exigida pelo jornal, a forma dos dois manifestos. O tom de um deles é descrito como “popular-brasileiro". De fato, é aos de baixo que interessa lutar pela democracia, uma vez que a ordem instituída obviamente exclui a todos que são considerados "menos iguais", seja por serem pobres, por viverem na periferia, por serem antimachistas, ou por serem artistas fora do circuito comercial, que tentam dar voz aos que não são ouvidos ou representados pela arte hegemônica. A eles é dada a possibilidade de ter consciência que o que está em jogo é mais do que uma disputa entre partidos políticos igualmente inaceitáveis. Os de baixo sabem o que estão fazendo com eles, por que o vivem, e é essa sabedoria que faz o tom do manifesto. 
A escolha do termo "casa-grande" para designar os autores do manifesto dos graúdos nos lembra que são descendentes diretos de escravocratas, que têm muita dificuldade de abrir mão de seus privilégios, mesmo que estes não tenham sido, infelizmente, ameaçados pelo governo que eles querem encerrar. $O$ tom é autoritário, a linguagem, a da propaganda, que evita o pensamento. Em contraposição, o outro lado reúne o povão, aqueles cuja diversidade é atravessada por um interesse comum, o de se contrapor aos que os excluem. Trata-se, como fica evidente, na escolha de palavras de Roberto, da especificação de mais um episódio da luta de classes como levada a cabo no Brasil. Perceber e nomear esse processo que estrutura a vida em nosso país é objetivo e realização central do projeto intelectual de Roberto.

Vou retomar alguns de seus ensaios centrais para mostrar qual a "adequação nacional e originalidade crítica" desse projeto. Começo com um clássico: "As ideias fora do lugar". Publicado em I973, é um dos textos centrais da crítica materialista contemporânea ${ }^{2}$. Sabemos que o objetivo primeiro desse ensaio é desenhar o chão histórico em que se constrói a obra de Machado de Assis, o primeiro grande escritor brasileiro que foi capaz de dar forma à matéria brasileira e, também por isso, objeto de estudo constante de Roberto. O ensaio parte da intuição, que todos temos, do caráter postiço das ideias no Brasil e examina como isso se organiza no século XIX como um dos resultados do choque entre as ideias normativas (mas não postas em prática nem mesmo lá) do liberalismo europeu - a liberdade de escolher um trabalho, o indivíduo livre, a igualdade perante a lei - e a vida real do nosso país, baseada no escravismo. Explica o fundamento dessa disparidade entre as noções importadas da Europa e as práticas brasileiras descrevendo a especificidade das relações de produção nos países descolonizados: a economia, que impulsiona o processo, é, como sabemos, voltada para as exigências do capital internacional, que a sustenta e que propaga as ideias hegemônicas. O choque destas com a situação local embaralha as noções do que é estrangeiro e do que é nacional, por exemplo, o escravismo - "abominação nacional", era uma empreitada capitalista, “abominação internacional”. Essa discrepância estrutural é a base da comédia ideológica que caracteriza o Brasil e incomoda a todos, progressistas e conservadores, nacionalistas e imitadores de ideias de fora, armando arapucas ideológicas de que poucos escapam. Roberto dá exemplos do descompasso que diz o Brasil tanto em suas manifestações da alta cultura, como na arquitetura e na própria crítica literária. Lembra casos mais corriqueiros, como o Hino da República que canta: "Nós nem cremos que escravos outrora/ Tenha havido em tão nobre país!", isso escassos dois anos após a abolição. Ou a proclamação do governo revolucionário de Pernambuco em I8I7, "Patriotas vossas propriedades, inda as mais opugnantes ao ideal de justiça, serão... sagradas”. No ponto de chegada, o ensaio demonstra como a boa - e hedionda - convivência dos opostos do liberalismo e do escravismo deu em obra-prima literária no Brasil, em um compasso comparável ao que se deu na Rússia. Isso confirma um dos achados do ensaio, a constatação de que "fora de seu lugar" as ideias adquirem nova potência de revelação, o que as torna de relevância geral. Para dar conta de seu material, os romancistas de países fora dos centros irradiadores de cultura e de ideologia têm que lidar com o funcionamento peculiar dos significados

2 Discuto esse ponto em “O avesso do atraso: notas sobre Roberto Schwarz” (CEVASCO, 2007). 
e valores deslocados. Esse contexto faz com que as obras, sob pena de ignorar o que define o movimento da sociedade que as molda, tenham que se construir na interação do mundo particular que desenham e das conexões inescapáveis com o geral que definem seu universo. Essa interação peculiar, descoberta crítica do ensaio, lhe confere uma amplitude que ultrapassa os limites usuais da crítica literária.

O ensaio traz, ainda, uma interessantíssima renovação de categorias: uma das mais produtivas é a noção de ideologia de segundo grau, que abre a possibilidade de entendimento da história mundial franqueada por esse funcionamento peculiar. Em seus locais de origem, as ideologias pelo menos descrevem a aparência da realidade, enquanto que aqui não descrevem, nem sequer falsamente, as aparências e não gravitam segundo uma lei que lhes seja própria. Isso contribui para torná-las risíveis. Claro que, na medida em que se tornam ridículas, essas ideologias podem parar de ofuscar, de enganar. Podem, ainda, apontar para seus próprios limites. Em mãos de mestre, como nas de Machado ou nas de Dostoievski, esse confronto entre ideias e lugar social acaba por possibilitar o aparecimento de um "critério para medir o desvario do progressismo e do individualismo que o Ocidente impunha e impõe ao mundo" (SCHWARZ, I977, p. 23). Em outras palavras, visto de países onde abortou a modernização, nome da ideologia mestra do Ocidente, o andar da carruagem do mundo tem outro ritmo, e esse ritmo pode ser apreendido na crítica cultural.

Não é menor o poder de revelação a respeito do país. Buscando descrever o contexto geral que forma e informa a obra de Machado, o ensaio acaba por atinar com as características fundamentais que estruturam as mais diversas manifestações da vida nacional. A fundante é a da interdependência econômica do fora e do dentro, o que as oposições entre metrópole e colônia, países atrasados e adiantados ou centro e periferia, como se diria mais tarde, e isso sem mencionar civilização e barbárie, progresso e atraso, moderno e antigo, têm como tarefa ideológica esconder. Esse ensaio contém, de forma sucinta, as preocupações e insights que vão moldar o modo de olhar de Roberto e torná-lo um mestre da crítica cultural contemporânea.

Veja-se como esse modo de ver está na base de sua avaliação crítica da apologia de uma estética do terceiro mundo, uma onda muito em voga nas décadas de 1970 e I980, que preconizava uma terceira via entre os dois lados da Guerra Fria, e uma suposta superioridade da arte dos países subalternos. Como de costume, Roberto vai direto ao ponto: bobagem medir superioridades entre entidades inexistentes, ou seja, uma estética única a nenhum dos três mundos. O lugar de origem não valoriza, e nem desvaloriza, as obras. "Em estética, como em política, o terceiro mundo é parte orgânica da cena contemporânea. Sua presença é a prova viva do caráter iníquo que tomou a organização mundial da produção e da vida" (SCHWARZ, I987a, p. I28). A força da arte está em sua negatividade, em expor a iniquidade, a opressão, o confinamento dos modos de vida que constituem a matéria incontornável das obras: "A mística terceiro-mundista encobre o conflito de classes, uma visão ingênua, ainda que violenta, dos antagonismos e sobretudo das interdependências internacionais" (SCHWARZ, I987a, p. I28). Trata-se, então, de mais uma ideia fora do lugar, embora originária da periferia.

O central não é ficar debatendo com ideias falsas, mas, como descreveria anos mais tarde, é compreender que, nos países criados pela descolonização, vivemos 
em um espaço "diverso mas não alheio" (SCHWARZ, I999b, p. 95), um espaço em que as categorias que sustentam as ideologias plasmadas nos países centrais não se aplicam com propriedade e nem podem deixar de ser aplicadas. Elas, aqui, giram em falso, ainda que sejam obrigatórias. O espaço é diverso porque a colonização obviamente não criava sociedades iguais às da metrópole, e nem a divisão posterior do trabalho internacional constrói igualdades. Mas trata-se de um espaço da mesma ordem, porque também ele é comandado pela dinâmica abrangente do capital. A marcha do país, ao contrário do que dizem os ideólogos do país do futuro, ou, mais recentemente, do país membro dos já não tão promissores Brics, a caminho de se integrar ao concerto das nações desenvolvidas, deve ser pensada como determinada pelo desenvolvimento desigual e combinado, como formulou Trotsky, do capitalismo mundial. Este, como se sabe, está longe de promover igualdade. Essa característica é o que impulsiona um movimento central da vida brasileira, que é um tema, já desenhado em "As ideias fora do lugar", que se torna fundante para a percepção de Roberto sobre o Brasil: em nosso país, a cada momento histórico em que a superação parece possível, repõe-se o atraso.

Talvez ao longo do século XX, a hora histórica mais emblemática desse movimento tenha sido o golpe militar de I964, que colocou um freio brusco nas aspirações para a superação da desigualdade histórica no país. O ensaio "Cultura e política, I964-I969" (SCHWARZ, 2008) aborda esse período crucial, que, para citar o filósofo Paulo Arantes (20I4), cortou a história do Brasil ao meio. Não por acaso, esse período tem sido constantemente lembrado em nossos dias pelas semelhanças do embate político entre interesses de classe antagônicos que a segunda década dos anos 2000 coloca, de novo, frente a frente.

É difícil exagerar a importância desse ensaio na produção intelectual da crítica materialista. Neil Larsen, que estuda o Brasil a partir dos Estados Unidos, acha que ele pode ser comparado ao I8 Brumário de Luiz Napoleão, na medida em que é capaz de colocar, "com toda sutileza e complexidade" (LARSEN, I995, p. 2I3 - tradução nossa), uma mudança profunda nas relações sociais e no papel do Estado que o golpe põe em cena. As consequências catastróficas para os de baixo dessas mudanças não se restringem ao caso brasileiro. O golpe foi um episódio central da Guerra Fria, a derrota das forças de oposição aponta para a vitória acachapante do lado capitalista, ceifando na base os ventos de mudança que agitavam muitos países e que definem, no imaginário social, os anos I960 como anos revolucionários.

O ensaio, publicado em I970, analisa o caso brasileiro do retrocesso mundial, um processo que mais uma vez ilustra a exatidão de se descrever o que se dá em nosso país como algo "diverso mas não alheio" ao que ocorre nos países centrais. Aqui como lá, esse momento mostra como houve um avanço significativo das forças conservadoras, que acabam por tingir as próprias ações e produções da Esquerda, inaugurando mais uma era do compromisso. $O$ ensaio vai contando como se caminha ao fracasso: em plena Guerra Fria, quando as "opções da história mundial" estavam abertas, o Partido Comunista acabou por fazer uma aliança com a burguesia nacionalista e modernizante, contra a burguesia latifundiária, corretamente avaliada como elemento sustentador dos aspectos arcaicos da vida nacional, que era preciso mudar. Porém, essa estratégia de aliar-se com o inimigo de classe levou 
a uma "visão desdentada" de oposição de esquerda, que abraçava a problemática burguesa de democratização e de modernização nacionalista. Um dos resultados foi um marxismo atado e provinciano, "especializado na inviabilidade do capitalismo, e não nos caminhos da revolução” (SCHWARZ, 2008, p. 78). Os dois lados do espectro ideológico compartilham uma visão sem contradições da modernização, desejo de todos. Estava aí já armado o pacto desigual entre visões políticas antagônicas que iria culminar na derrota fragorosa da visão progressista - como sabemos, no momento do golpe, as classes dominantes se uniram em torno da bandeira do anticomunismo - repetindo, mais uma vez, o movimento central, já comentado aqui, de que, a cada momento de possível superação no Brasil, repõe-se o atraso. As possibilidades de integração social em benefício de todos são ceifadas pela instauração do governo militar, e pela reversão da ordem que repõe as forças da permanência, fechando um período que poderia ter sido de grandes avanços 3 .

Entretanto, esse processo não está isento de contradições. Mais uma vez, é fazendo a leitura crítica da produção cultural do período que Roberto vai especificar as peculiaridades desse momento emblemático. Ele começa por constatar uma dissonância: nos primeiros anos do Golpe, "apesar da ditadura da direita, há relativa hegemonia cultural da esquerda" (SCHWARZ, 2008, p. 70) com produções de grande qualidade e alcance. Roberto examina exemplos dessa produção, e penso que os dois que mais de perto cristalizam as forças que disputam a hegemonia no período são o método Paulo Freire e o Tropicalismo. Sabemos que o método, que foi reconhecido mundialmente, se notabiliza pela percepção correta de que impedir a leitura da palavra equivale a impedir a leitura do mundo, e a consequente participação nos seus rumos. É parte estrutural da exclusão social, que não dá voz aos que deixa à margem. O método inverte esse movimento. Ao partir da experiência do aluno - no caso da alfabetização nos anos I960, no mais das vezes, um adulto -, ele já o inclui mesmo antes de ensiná-lo a ler. Parte dos alunos a escolha das "palavras geradoras” que vão nortear o aprendizado da leitura e a discussão da conjuntura que os exclui. As implicações políticas do método mostram os caminhos possíveis para a superação do atraso constitutivo do país. Ela passa pela integração social dos excluídos pela dominação do capital, que comanda a dinâmica do processo e se apresenta como a opção progressista e moderna, como se fosse aceitável o progresso de apenas alguns, apagando a imensa dívida social que o país carrega desde seus primórdios. Mais uma vez, estamos diante da oposição atrasado/moderno.

A capacidade de figurar essa dualidade constitutiva do Brasil é uma das forças artísticas do também muito conhecido Tropicalismo. Esse movimento, que abarcou o teatro, o cinema, a televisão, as artes plásticas e, de forma mais emblemática, a música, se notabiliza por juntar as imagens do país arcaico e do moderno, buscando uma fusão, na aparência bastante atraente, entre os dois Brasis. Já me referi em outra ocasião ${ }^{4}$ a um exemplo claro dessa figuração de opostos ao comentar o disco Panis et circensis de I968, um dos marcos da produção tropicalista. O amálgama já começa na capa, um retrato posado de membros do movimento, com Gilberto Gil vestindo

3 Retomo aí ideias que já apresentei em "A crítica cultural lê o Brasil” (CEVASCO, 20I6).

4 Para uma explicação mais detalhada, ver meu “A crítica cultural lê o Brasil” (CEVASCO, 20I6). 
uma túnica, roupa ultramoderna para a época, com motivos que remetem à estética hippie, então moda nos países centrais. Na mão, ele carrega um retrato de formatura, supertradicional. Caetano Veloso segura outro retrato com tons antiquados, mostrando a cantora Nara Leão; ao lado, o maestro Rogério Duprat segura um penico como se fosse uma xícara de chá. O repertório do disco se abre com uma composição de Gilberto Gil e dos Mutantes, "Miserere nobis”, com seu sugestivo refrão "Misere-re nobis/ora, ora pro nobis/ é no sempre será, ô, iaiá/ É no sempre, sempre serão”. As faixas do disco repetem a superposição do supermoderno, "Bat macumba", de Gil, com o antigo, o "Coração materno" (I937), uma música kitsch que havia sido sucesso na voz do cantor brega Vicente Celestino. Os arranjos musicais ecoam a mistura: guitarras ultracontemporâneas e internacionais com batidas mais tradicionais da música brasileira. O matiz predominante no disco é o do deboche e da irreverência, mas há certo tom de familiaridade profunda com os arcaísmos da vida brasileira, que são repostos e tomam novo significado na convivência com o ultramoderno. Está tudo amalgamado na mesma geleia geral onde chafurdamos todos. Como diz uma das faixas do disco cuja letra ecoa a imutabilidade da situação nacional: "Ê bumba iê iê boi/ Ano que vem, mês que foi/ Ê bumba iê iê iê/É a mesma dança, meu boi”.

Que ponto de vista sobre o Brasil se expressa nessa construção artística? Por um lado, trata-se de uma representação bastante fiel do que se dá na vida nacional, onde o passado está sempre pronto a reaparecer. Na nota que prefacia a republicação, em I978, de "Cultura e política, I964-I969", Roberto diz que sua intenção era "assumir literariamente [...] a atualidade de então. Assim, quando se diz 'agora', são observações, erros e alternativas daqueles anos que têm a palavra. O leitor verá que o tempo passou e não passou" (SCHWARZ, 2008, p. 70).

Essa última frase condensa toda uma história nacional, que reconhecemos a cada tanto. A permanência do arcaico não está apenas na música. Roberto lembra como o Golpe faz reaparecer fantasmagorias do atraso que se pensava estarem superadas. Vale a pena citar na íntegra para que salte à vista a medida de como isso se repete outras vezes na nossa história:

Agora, no rastro da repressão de 64, era outra camada geológica do país quem tinha a palavra. “Corações antigos, escaninhos da hinterlândia, quem vos conhece?” Já no pré-golpe, mediante forte aplicação de capitais e ciência publicitária, a direita conseguira ativar politicamente os sentimentos arcaicos da pequena burguesia. Tesouros de bestice rural e urbana saíram à rua, na forma da "Marcha da família, com Deus pela liberdade", movimentavam petições contra divórcio, reforma agrária e comunização do clero, ou ficavam em casa mesmo, rezando o “Terço em família”, espécie de rosário bélico para encorajar os generais. Deus não deixaria de atender a tamanho clamor, público e caseiro, e de fato caiu em cima dos comunistas. No pós-golpe, a corrente da opinião vitoriosa se avolumou, enquanto a repressão calava o movimento operário e camponês. Curiosidades antigas vieram à luz, estimuladas pelo inquérito policial-militar que esquadrinhava a subversão. - O professor de filosofia acredita em Deus? - O senhor sabe inteira a letra do Hino Nacional? - Mas as meninas, na Faculdade, são virgens? - E se forem praticantes do amor livre? (SCHWARZ, 2008, p. 82). 
Esse movimento, que Roberto chama no ensaio de "revanche da província", corrobora um dos eixos da junção de opostos que caracteriza a imagem tropicalista. $\mathrm{O}$ outro é a abertura ao mundo contemporâneo, expressa no uso de modos de expressão da vanguarda internacional. Mas o modo dessa junção traz embutido um julgamento histórico: não se trata de uma contradição, que poderia ser resolvida em uma síntese que a superasse, mas de uma junção de opostos irreconciliáveis: "a imagem tropicalista encerra o passado na forma de males ativos ou ressuscitáveis, e sugerem que são nosso destino, por isso não cansamos de olhá-la” (SCHWARZ, 2008, p. 92). O destino não pode ser mudado, e, por isso, a ação política que essa concepção enseja só pode ser conformista. E, mais uma vez, a arte capta uma das sementes do tempo, na medida mesma em que o Tropicalismo concretiza em arte uma característica que marcaria muito da ação política da esquerda, cujo horizonte rebaixado não admitia mais superação, só reformas no statu quo. Rearma-se já aí o "sistema de conciliação" que vai imperar na esquerda e desembocar em acomodações.

O tema do nacional e do estrangeiro reaparece com força no final dos anos I980, quando a noção de globalização começa a desconstruir essa oposição. "Nacional por subtração", escrito em I986, mostra como as posições mais comuns sobre a cultura nacional traduzem posições sobre os rumos da nossa sociedade e recolocam as opções de sempre, entre uma cultural nacional e outra estrangeira, agora no contexto da internacionalização do capital vitorioso. Como se situar diante dos novos termos que a nova versão da velha ordem mundial coloca? O que acontece com as duas opções, igualmente falsas, de uma via nacional e uma internacional? Por que elas ocupam tanto espaço no debate no Brasil?

A pergunta, explica Roberto, é falsa porque pressupõe que a situação internacional deixe abertas opções de não integração. Isso modifica os termos da velha discussão. Por um lado, nesta "atmosfera 'global', de mitologia unificada e planetária, o combate por uma cultura 'genuína' faz papel de velharia” (SCHWARZ, I987b, p. 34). Fica patente seu caráter ilusório, além de provinciano e complementar, de formas arcaicas de opressão. Mas tem sempre alguém para embarcar nessa canoa furada e dizer: "então agora não seremos mais arcaicos, acabaram as formas antigas”, embora, como lembra nosso autor, as antigas formas de opressão continuem na ordem do dia, por mais que sejam escamoteadas no debate intelectual. Mais do que isso, ao descartar o lado nacional da questão, temos um argumento que parece fazer sentido, já que o de fora é sempre melhor. Claro que ninguém acrescenta que a dimensão internacional da cultura funciona muito mais como legitimação pura e simples dos mídias e suas visões estereotipadas. Arma-se aí mais um quadro de oposições simétricas: os que se dizem nacionalistas atacam o imperialismo mas se calam diante da opressão burguesa, base da nação, enquanto os antinacionalistas

[...] assinalam a dimensão autoritária e atrasada de seu adversário, com carradas de razão, o que no entanto faz crer que o reinado da comunicação de massas seja libertário ou aceitável do ponto de vista estético. Uma posição crítica e moderna, conformista no fundo. (SCHWARZ, I987b, p. 35).

O debate, embora acirrado, não avança a discussão e serve, de fato, para esconder o essencial, ou seja, a exclusão sistemática dos pobres, tanto do mundo da cidadania, 
quanto do da cultura. Essa exclusão é parte fundamental do que define nosso atraso. Como se vê, o amálgama entre o mais moderno e o mais arcaico, que Roberto já havia mostrado ao analisar o Tropicalismo, continua válido e atuante, cada vez com uma inflexão específica, mas sempre escondendo o conformismo sob roupagem modernizante. Temos aí mais uma repetição de um movimento estrutural da vida em países periféricos. Certamente que, para nosso autor, a questão não é arbitrar entre duas posições impossíveis, a questão é dar o "passo globalizante" e pensar "o nosso 'atraso' como parte da história contemporânea do capital e de seus avanços" (SCHWARZ, I987b, p. 47-48).

Esse é o programa que estrutura seu ensaio "Fim de século", que começou a ser elaborado em I994, quando já se torna claro, para os que sabem ver, que se está redesenhando o velho funcionamento do mundo, que agora aparece com roupagem específica que é preciso descrever para apreender "que horas são". Quais os impactos da terceira revolução industrial, do estabelecimento do neoliberalismo e da época de dominação global do capitalismo e da eliminação de alternativas sobre a matéria brasileira?

Roberto retoma nesse ensaio a análise da conjuntura mundial feita pelo alemão Robert Kurz. Em seu O colapso da modernização argumenta que a impossibilidade de viabilizar o desenvolvimento das nações (mesmo das que, como o Brasil, se mobilizaram fortemente para isso) gera sociedades pós-catastróficas, onde a integração não é mais possível. Seriam sociedades cuja dinâmica é regida pela desagregação, pelo abandono de noções de um projeto comum que se aplicasse a todos ou mesmo de uma ideia de nação coesa. Vale a pena ressaltar que não se trata de um diagnóstico de erros políticos ou de condução da economia, embora todos esses tenham existido e continuem a piorar a situação. Na leitura de Kurz, que Roberto endossa, trata-se de um problema estrutural, inerente ao funcionamento do capital. A modernização tão almejada é necessariamente excludente, somos modernos, e a parte que nos tocou no processo é esta. Nesse sentido a modernização, como o liberalismo antes dela, é uma ideia fora do lugar. Assim como no caso do liberalismo, os seus resultados na periferia abrem espaço para uma extensa crítica da ideologia da modernização. Só que não foi exatamente o que se deu.

$\mathrm{Na}$ academia, o pensamento teórico, cuja tarefa histórica seria contar a história real do tempo, seja do ponto de vista do centro, seja do da periferia, ou, melhor ainda, da intersecção entre os dois, era dominado pelo pós-estruturalismo, cujo braço mais influente era o desconstrucionismo. Como se recordará, esse modo de pensar se caracterizava pela destruição retórica das oposições binárias que organizam nosso discurso e interrogava a possibilidade de se chegar a uma verdade ou de se apresentar uma interpretação. Trata-se de uma crítica que se apresentava como radical, embora não se detivesse na base material que sustenta o pensamento e condenasse qualquer modelo que apresentasse relações de causalidade ou pretensões a elucidar as interligações entre fragmento e todo. Como dizia Lyotard (I983, p. 96), um dos representantes dessa vertente, nós "já pagamos bastante a nostalgia do todo e do uno, da reconciliação do conceito e do sensível, da experiência transparente e comunicável. A resposta é: guerra ao todo, testemunhemos o inapresentável, ativemos as diferenças, salvemos a honra do nome”. 
Como já acontecera com o Tropicalismo, por um lado, essa crítica radical, porém inócua, capta a energia do seu tempo. De fato, o terremoto do colapso da modernização interroga todas as categorias usadas para pensar o Brasil como centro e periferia, desenvolvimento e estagnação, moderno e arcaico, progresso e atraso. $\mathrm{O}$ próprio Roberto lembra, em "Fim de século", que, em especial no contexto brasileiro,

[...] a desestabilização dos sujeitos, das identidades, dos significados, das teleologias - especialidades [...] do exercício de leitura do pós-estruturalismo - adquiriu uma dura vigência prática. Assim o desenvolvimento nacional pode não ter sido nem desenvolvimento, nem nacional [...]. (SCHWARZ, I999a, p. I58).

O mesmo se dá com a categoria de nação:

[...] o discurso desconstrucionista sobre os preconceitos e enganos embutidos na ideia abstrata de nação tem pouca relevância, e passa à margem do processo efetivo. A presente desintegração nacional é uma realidade material da história contemporânea, e a distância que separa as suas condicionantes técnico-econômicas dos trocadilhos filosóficos em moda, ou talvez já ex-moda, é patética. (SCHWARZ, I999a, p. I60).

Mais uma vez a verificação recíproca entre as formulações vindas do centro e a realidade da periferia fornece uma matéria histórica densa, que abre a possibilidade de se instaurar uma perspectiva crítica sobre os limites das ideologias de dentro e de fora. Seria o caso de aparecer um pensamento que fizesse, para ficar no mais óbvio, uma extensa crítica da ideologia da modernização. Mas não apareceu nenhum Machado de Assis para amalgamar as contradições em um conjunto revelador, que iluminasse a vida ideológica como um todo.

Pode ser por isso que, quando, em mais uma das voltas da globalização, começou a circular no debate intelectual uma nova versão da modernização e de seus efeitos culturais nas trocas entre as nações, Roberto se volte, ainda uma vez, ao nosso maior escritor. Agora, a nova maneira de pensar o trânsito entre diferentes tradições literárias é a literatura mundial. O termo remete, em um primeiro momento, ao impulso de Goethe de facilitar o entendimento entre as nações através do conhecimento de suas literaturas e também, logo em seguida, a Marx e Engels que, no Manifesto, observam que, assim como a burguesia revolucionou a produção nacional, usando matérias-primas de diferentes países, e comercializou mercadorias por todo o globo, "[os] produtos intelectuais de cada nação tornam-se bens comuns [...], e a partir das muitas literaturas locais, nacionais, forma-se uma literatura universal” (MARX; ENGELS, 20I2, p. 46). Mas, usando ainda outra expressão de Marx, ela não renasce em condições de sua própria escolha, e suas pretensões à troca e ao enriquecimento mútuos têm que se haver com as condições e os limites que a nova fase do capital lhe impõe.

Assim, os ideólogos do novo momento apressam-se a celebrar a nova moda intelectual como mais um dos efeitos benéficos de mais uma versão da ordem mundial de sempre. Por exemplo, para David Damrosch, primeiro presidente da Associação da Literatura Mundial, a nova maneira de pensar a produção literária é em termos da circulação das diferentes literaturas que enseja um modo de ler que 
faz com que uma obra produzida em uma nação específica viaje para além de suas fronteiras e entre em diálogo com a cultura que a recebe. Mais um sonho liberal.

Em uma perspectiva mais realista, o crítico marxista Franco Moretti, uma das vozes centrais no debate, considera que literatura mundial não é um objeto, mas o nome de um problema. Ele propõe que a pensemos usando como base a teoria do sistema-mundo de Immanuel Wallerstein, que descreve o mundo sob a égide do capital como uma unidade dentro de uma única divisão do trabalho, com múltiplos sistemas culturais, constituída por um centro, uma periferia e uma semiperiferia, todos regidos pela mesma lógica sistêmica. Essa formulação remete, é claro, à do Trotsky da teoria do desenvolvimento desigual e combinado, ou à de um mundo que cria espaços, na formulação de Roberto, também já citada aqui, diversos mas não alheios ao sistema que os rege a todos. Moretti se propõe a lidar com a questão da literatura mundial buscando "as semelhanças nas diferentes desigualdades e chegar a princípios gerais que lhe possibilitem ver a literatura mundial como sistema, mas um sistema de variações, que é uno e ao mesmo tempo não é uniforme" (MORETTI, 2000, p. 56 -tradução nossa). Para dar conta dessa tarefa, propõe um sistema de leitura a distância, que busca descobrir os padrões e as regras não ditas de um número grande de obras.

Em 2003, dando uma palestra na Universidade de São Paulo sobre seu método, Moretti foi confrontado por Roberto com uma questão que, ilustrando a produtividade de um debate intelectual sério, reaparece no ensaio do mesmo ano em que Moretti responde às leituras de vários críticos de seu ensaio-programa. A pergunta que é citada no ensaio é: "Será que esse tipo de história literária baseada em princípios gerais e abstrações metodológicas ainda pode ser o que a tradição demanda de seus pensadores, uma forma de crítica social?” (MORETTI, 2006, p. 84 - tradução nossa). Ou seja, será que nas novas condições do funcionamento do sistema-mundo é possível manter o trabalho da crítica? Essa é uma questão que envolve muito mais do que um debate acadêmico sobre o estado atual das diferentes literaturas, uma vez que, como diz Moretti, nossa opinião sobre o que é a literatura mundial é também uma opinião sobre o estado atual do mundo.

No mesmo ensaio-resposta, ele diz:

[...] o ponto central aqui é este: se há uma forte pressão exercida por algumas literaturas sobre as outras (e parece que todos concordamos a esse respeito), então não teríamos que ser capazes de reconhecer isso no interior da própria forma literária, na medida em que as formas são, nas palavras de Schwarz, o abstrato de relações sociais específicas? (MORETTI, 2006, p. 84 - tradução nossa).

O ensaio de Roberto, "Leituras em competição", publicado no livro Martinha versus Lucrécia (20I2a), pode ser lido como uma resposta esclarecedora a essas questões que a nova volta do velho parafuso do debate nacional/estrangeiro coloca. Com ele aprendemos muito sobre o estado geral do mundo de hoje. A ocasião é a recepção internacional de Machado de Assis, que em tempos de confecção de um novo cânone internacional, para constituir a literatura mundial, se transforma em um clássico universal. Uma das questões aí é resolver: quem define o que é universal ou, colocando em meus termos toscos, quem detém o poder de resolver o que é o universal? 
Mas, antes, é preciso lembrar que o reconhecimento internacional de Machado poderia ser algo bastante positivo, a ser celebrado do lado de cá: afinal, o próprio Roberto já tinha chamado a atenção de como sua técnica narrativa o coloca entre os grandes das literaturas europeia e norte-americana, as representantes do tal universal que nos aceita apenas em seus próprios termos. No entanto, os modos dessa consagração nos países centrais, em especial no mais central de todos, os Estados Unidos, mostram como funcionam esses termos da integração no concerto das nações. No ensaio, Roberto dá um exemplo típico dos modos dessa consagração: em uma resenha de 2002, na New York Review of Books, sobre as traduções dos romances de Machado para o inglês e de obras críticas sobre ele, Michael Wood defende que não é preciso se interessar pela realidade sócio-histórica brasileira, matéria de Machado, para apreciar sua maestria. Ele elogia a capacidade de elucidação da leitura local de Roberto, que ele considera um grande crítico, capaz de demonstrar as determinantes histórico-sociais da obra de Machado e sua maneira de apreender a realidade local, mas que não é isso que torna o escritor um mestre da literatura universal. Ele defende que

Machado é nosso contemporâneo, porque suas preocupações ocorrem em todos os lugares, assim com ocorrem as formações de nuvens ou os protestos políticos, ... e certamente poderíamos encontrá-las em outros locais, e é pouco provável que um dia não as encontremos mais. (WOOD, 2002 - tradução nossa).

Falta um passo para se cair na velhíssima fórmula de neutralizar o sentido da literatura e desconsiderar seu valor cognitivo. O valor estético de Machado residiria em sua capacidade de lidar com os valores eternos da humanidade, termos, como sabemos, de muito difícil especificação. A leitura que considera a história local fica assim encolhida como acanhada e de pouco interesse.

Mas, como já aprendemos com Roberto, desde, pelo menos, o seminal "As ideias fora do lugar", as noções de local e de estrangeiro, ou mesmo específico ou universal, são altamente complexas, e só podem ser compreendidas na dinâmica histórica que lhes dá sentido. Tanto quanto local e estrangeiro, universal e específico são categorias interconstitutivas, e só podem ser aprendidas em relação dialética. Só podem ser valorizadas, ou apequenadas, no interior do contexto sócio-histórico que as determina, e cujas linhas de força elas concretizam. O universalismo vazio defendido por Wood, e implícito em muitas das discussões sobre o novo cânone mundial, pode ser lido como figura da recusa da crítica cultural em voga em enfrentar o que torna possível esse monopólio sobre o universal e essa necessidade de ignorar o conteúdo sócio-histórico real, formalizado nas obras literárias. É curioso que esse apagamento das questões efetivas de poder e do privilégio de classe embutido nessas relações ecoe o dos protagonistas de Machado, que vão expondo sua desfaçatez solidamente apoiada na desorganização social da periferia, que potencializa as características que constituem o sistema que nos rege a todos. Com menos freios do que no centro, essa cegueira ideológica dos de cima acaba por dizer, como ensinam Roberto e Machado, a verdade da organização social burguesa em geral. Mesmo em tempos que procuram ocultar as discrepâncias reais sob o manto de termos neutralizados como "globalização", "universal”, “diálogos entre culturas”, o ponto de vista da periferia é 
ainda constitutivo e revelador. Em um contexto de opacidade generalizada, o ponto de vista da periferia ainda é o lugar que oferece a visibilidade mais acurada. A sua realidade drástica e dura demonstra as persistências no sistema que rege o globo que, estas sim, tornam Machado nosso contemporâneo.

E agora, ainda uma outra vez, é preciso interrogar as categorias que organizam a discussão entre nacional/estrangeiro, local/universal. Em uma tirada explicitamente irônica, não muito comum na sua escrita sutil e engenhosa, após elencar leituras que fazem paralelos entre Machado e os demais membros do cânone dito universal, ele pergunta: "Por que supor, mesmo tacitamente, que a experiência brasileira tenha interesse apenas local, ao passo que a língua inglesa, Shakespeare, o New Criticism, a tradição ocidental e tutti quanti seriam universais?” (SCHWARZ, 20I2a, p. 29).

Claro que a questão não é arbitrar quem tem razão nessa polêmica falsa e sem apoio no real. Como de costume, Roberto a responde à situação através da análise de um texto. No caso, uma crônica de Machado que trata exatamente desses temas. Escrita em I894, narra do ponto de vista universalista de um narrador típico da intelectualidade periférica: "culto e bem-posto, sócio das classes dominantes do mundo que o desabona”. Ele nos conta aí, com considerável ironia e distanciamento, uma história que teria lido em um jornal provinciano: ameaçada em sua honra, Martinha, uma moça simples porém "moderna", natural da Cachoeira, no interior da Bahia, mata com um punhal um João que a assedia. Nosso narrador, finíssimo, compara esse episódio da Martinha da Cachoeira com a punhalada com que Lucrécia se suicida após ter sido estuprada por um nobre romano, e conclamado o pai e o marido que a vingassem, segundo a história clássica narrada por Tito Lívio. Enquanto a crônica avança, o narrador, sempre empoladíssimo, vai se questionando se Martinha, afinal, vista como bárbara e exótica, não tem lá seu valor. Os termos da comparação, sempre veiculados na linguagem cultivada e cheia de alusões recheadas de literatice e de referências à alta cultura de fora, vão se embaralhando, e o jogo de superioridade/inferioridade do local e do universal, do provinciano e do clássico vai trocando de sinal. A certa altura, o narrador, sempre usando a linguagem que exclui os não iniciados, lamenta a injustiça de a história lembrar o punhal fictício de Lucrécia e relegar ao esquecimento o punhal real de Martinha. Não lhe ocorre perceber que a própria linguagem que usa faz pacto com os que deixam de lado as Martinhas, e também os que, como o narrador, fazem uso de segunda mão dos modos de dizer que vêm de fora. Sem se dar conta de suas afinidades com os que compõem a realidade relegada, ele fecha sua crônica dizendo: "Mas não falemos mais em Martinha”.

Na leitura de Roberto fica claro que essa crônica coloca os diferentes aspectos que a questão da literatura mundial põe em funcionamento e suas implicações para o lado discursivo das disputas que definem o espaço internacional pretensamente universal, mas saturado de jogos de interesses e de poder. A prosa do narrador ilustra bem o cosmopolitanismo vazio dos que pretendem ignorar a realidade do local em favor de uma pretensa superioridade de um universal abstrato. Essa realidade é justamente o que o crítico Wood (2002), citado acima, descarta como não sendo fundamental para colocar Machado entre os grandes, evidenciando os preços a serem pagos para entrar no tal cânone universal. As iluminações mútuas que o embate 
contemporâneo em torno do local e do universal joga sobre a organização geral do mundo, onde poucos decidem o que pode ser considerado universal, se expressam na leitura atenta da forma da crônica. Diz Roberto:

O frequentador carioca de Tito Lívio, que zomba dos compatriotas desfavorecidos e no íntimo se ofende com o destino que lhes cabe, à margem do mundo, não é menos pitoresco do que Martinha. Mas não se pode dizer que seja uma figura localista, pois os seus ressentimentos derivam claramente da história contemporânea em sentido amplo, a qual expressam e cujo quadro de desigualdades e humilhações internacionais não diz respeito só aos brasileiros, mas a todo mundo - embora de maneiras diferentes ${ }^{24}$. Ao fazer desta personagem o seu narrador, ou, por outra, ao desuniversalizar o narrador cosmopolita - uma operação formal decisiva -, Machado dessegregava a matéria local. Esta saía de seu confinamento histórico e via-se intermediada por um vivíssimo jogo de interesses de classe atrasado-modernos, nacionais e internacionais, disfarçados de universais. Por baixo da engrenagem retórica, lógica e estética do particular e do universal, pressionando-a e dando-lhe verdade, como um imenso subentendido, há luta de classes, luta entre nações, patamares desiguais de acumulação cultural, além de luta artística e crítica. [...]

24. Sobre a textura histórico-mundial dessa ordem de ressentimentos, ver Paulo Arantes, Ressentimento da dialética. Rio de Janeiro: Paz e Terra, I996.

(SCHWARZ, Roberto, 20I2a, p. 42).

Mais uma vez, fica evidente o potencial cognitivo de uma crítica que sabe que seu trabalho é fundamental para elucidar os andaimes do mundo. De novo, como diz Roberto, a relevância da crítica está no fato de que o

[...] trabalho da figuração literária é um modo substantivo de pensamento, uma via sui generis de pesquisa, que aspira à consistência e tem exigência máxima. Seu resultado não é a simples reiteração da experiência cotidiana, a cuja prepotência se opõe, cujas contradições explicita, cujas tendências acentua, com decisivo resultado de clarificação. (SCHWARZ, Roberto, 20I2b, p. 287-288).

Nada mais a acrescentar.

$* * *$ 
MARIA ELISA CEVASCO é professora titular do Departamento de Letras Modernas da Faculdade de Filosofia, Letras e Ciências Humanas da Universidade de São Paulo (DLM/FFLCH/USP).

E-mail: maece@usp.br

https://orcid.org/0000-0003-I253-5996

\section{REFERÊNCIAS}

ARANTES, Paulo. Ressentimento da dialética. Rio de Janeiro: Paz e Terra, I996.

. Debate sobre "Cultura e política", FFLCH-USP, 7 de abril de 20I4.

CEVASCO, Maria Elisa. A crítica cultural lê o Brasil. In: LOUREIRO, Isabel; SINGER, André (Org.). As contradições do lulismo: a que ponto chegamos. São Paulo: Boitempo, 20I6, p. 25I-279.

. O avesso do atraso: notas sobre Roberto Schwarz. Terceira Margem, v. II, n. I6, 2007, p. 9-26.

LARSEN, Neil. Reading North by South. Minneapolis: University of Minnesota Press, I995.

LYOTARD, Jean-François. Resposta à questão o que é pós-moderno. Arte em Revista, n. 7, agosto de I983.

MARX, Karl; ENGELS. Manifesto do Partido Comunista. Trad. Sergio Tellaroli. São Paulo: Companhia das

Letras, 2012.

MORETTI, Franco. Conjectures on world literature. New Left Review, I, January/February, 2000. . The end of the beginning. New Left Review , 4I, September/October 2006.

SCHWARZ, Roberto. As ideias fora do lugar. In: . Ao vencedor as batatas. São Paulo: Livraria Duas

Cidades, I977, p. 9-3I.

. Existe uma estética do Terceiro Mundo?. In: . Que horas são?: ensaios. São Paulo: Companhia das Letras, I987a, p. I27-I28.

. Nacional por subtração. In: Que horas são?: ensaios. São Paulo: Companhia das Letras, I987b, p. 29-48.

. Fim de século. In: . Sequências brasileiras: ensaios. São Paulo: Companhia das Letras, I999a,

p. I55-I62.

. Um seminário de Marx. In: . Sequências brasileiras: ensaios. São Paulo. Cia das Letras, I999b, p. 86-I05.

. Cultura e política, I964-I969, In: . O pai de família e outros estudos. (I978). São Paulo: Companhia das Letras, 2008, p. 70-ᄑII.

. Leituras em competição. In: . Martinha versus Lucrécia: ensaios e entrevistas. São Paulo:

Companhia das Letras, 20I2a, p. 9-43.

. Na periferia do capitalismo. Entrevista concedida a Luiz Henrique Lopes dos Santos e Mariluce

Moura. Revista Pesquisa Fapesp, I03, setembro de 2004, p. I05. Republicado em .Martinha versus

Lucrécia: ensaios e entrevistas. São Paulo: Companhia das Letras, 20I2b, p. 280-304. . Folha de S. Paulo. Ilustríssima, Io de abril de 20I6, p. 6.

WOOD, Michael. Master among the ruins. The New York Review of Books, v. I9, n. I2, July I8, 2002. 